\title{
Large-Scale, Low-Frequency Barotropic Circulation on Continental Margins
}

\author{
SCOTt B. Power, Roger H. J. Grimshaw and Jason H. Middleton \\ The University of New South Wales, Kensington, NSW, Australia
}

(Manuscript received 30 May 1989, in final form 2 November 1989)

\begin{abstract}
Analytic solutions are obtained for forced, barotropic circulation at subinertial frequencies over a bilinear continental margin (shelf and slope) in situations where bottom friction is important. Three different alongshore forces are considered: wind-stress, offshore oceanic pressure gradients and offshore currents. Forcing functions are assumed to vary sinusoidally in time and in space alongshore. Steady models are found to perform adequately provided that the forcing functions do not move in the same direction as the free modes (continental shelf waves) propagate. Near resonance, when the alongshore velocity of the forcing approximates that of a free mode, the response is dominated by the mode. In the case of wind forcing, signals are trapped nearshore. If the shelf break occurs within this trapping length (as occurs near resonance) the shelf width becomes the effective trapping length. In this instance there can be significant horizontal shear in the alongshore velocity on the shelf near the shelf break.

When the velocity of an oceanic, alongshore pressure gradient signal approximates that of a free mode, the signal can be amplified towards the coast. For example, near a mode 2 resonance the signal is a maximum near the coast with a secondary maximum on the continental slope, near the shelf break. This amplification is in stark contrast to the solution forced by a signal which is either stationary or moving in a direction opposite to that in which the free modes propagate, which simply fall away from their maximum values offshore, resulting in weak coastal circulations.

Bottom friction affects the free continental shelf waves in three ways: their phase speeds are reduced, they decay with time and their altered structures exhibit phase differences across the continental margin whereby the flow nearshore leads that offshore in time. As a result, increased bottom friction reduces the response at resonance, broadens the range of frequencies over which responses are increased and detunes, or shifts, the frequency at which resonance occurs to a lower value. At practical parameter values, the reduction is minimal for the first mode but can be substantial for the second.
\end{abstract}

\section{Introduction}

The passage of weather systems over the ocean has long been known to drive circulations over the continental margin, primarily through the agency of the longshore component of wind stress (Buchwald and Adams 1968; Gill and Schumann 1974). There is now an enormous amount of observational evidence for such circulations and, in particular, the important role played by continental shelf waves (CSWs). A number of theoretical models have been developed which encapsulate the fundamental dynamics.

As we have come to understand the wind-driven circulation, it has become apparent that the deep ocean must also play an important role in the dynamics of the coastal ocean, especially at subinertial frequencies. Interactions between the deep ocean and the continental margin are a common feature on margins near major offshore current systems and have been observed near the Gulf Stream and the East Australia current.

Corresponding author address: Scott Power, Climate Research Group, Department of Meteorology, McGill University, Montreal, Canada.
The interactions can take the form of topographic Rossby waves (Louis et al. 1982; Aikman et al. 1987), detached warm-core rings (Joyce 1984), eddies or direct current forcing (Freeland et al. 1986), for example. In contrast to the wind-driven case, there are only a few theoretical models which have been used to examine the dynamics of circulations driven by offshore forcing. (Louis and Smith 1981; Romea and Allen 1982; Denbo and Allen 1983; Middleton 1987; Weaver and Middleton 1989).

Our aim in this paper is to develop a simple model for the barotropic response to both wind and offshore forcing and to subsequently determine the role played by frictionally modified CSWs in the forced response. The model used is an extention of that used by Power et al. (1988, hereafter referred to as PMG) in which the shelf is modeled by a depth profile with a single, constant slope. PMG is, in turn, an extension of the frictionally dominated, steady-state theories of Csanady (1978) and Middleton (1987) which do not allow for subinertial frequency variability. Power et al. found that free shelf waves could be considerably slowed at realistic frictional values and that the maximum response to forcing (either wind stress or offshore) is 
largely determined by resonances especially for the lowest mode. However, the effect of an adjoining continental slope was not explicitly considered since the offshore forcing functions were applied at the shelf break where the shelf and slope meet. This presumes that significant signals are transmitted across the slope. In the present paper, the more general assumption that the signal need only reach the outer edge of the slope is made. We are thus able to determine the importance of the continental slope in the barotropic dynamics.

In the case of the response to offshore forcing, we are fortunate in having the numerically determined results of Chapman and Brink (1987). They studied the response to offshore, fluctuating pressure fields on a continental margin (the coastal region consisting of both the shelf and slope) with a coastal depth of $30 \mathrm{~m}$ adjoining a baroclinic ocean $3 \mathrm{~km}$ in depth and were able to draw the following conclusions: (i) largest responses occur near free-wave resonances when friction is not dominant, (ii) the shelf response is nearly always barotropic, (iii) deep-ocean flows are ineffective at forcing shelf flows when their energy lies in frequency bands below $0.05 \times 10^{-4} \mathrm{~s}^{-1}$, and (iv) the slope response at very low frequencies is insensitive to the shelf geometry. The first conclusion confirms the analytical results of Romea and Allen (1982) and Denbo and Allen (1983). Neither of these studies however, concentrated on the dynamical importance of either frictional or topographic variations as we shall do here.

In addition to examining the validity of the latter two conclusions given above the following questions will also be addressed. How does the response over the bilinear margins compare to those presented by PMG? When do the simpler, steady models provide an accurate representation of the time-dependent results? What are the major differences between the wind and offshore driven responses? Under what circumstances is the continental slope an effective barrier to the transmission of an ocean signal? How do the forced solutions vary with frequency? How does the structure, phase speed and damping rate of the free modes depend upon friction and bathymetry?

The plan of this paper is as follows. The problem is formulated in section 2 . The solutions are then determined and described in section 3 . In section 4 the modal frequencies and structures are determined so that the forced solutions can be better understood. Finally, the key results are summarized and conclusions drawn in the last section.

\section{Formulation}

In formulating the problem, a right-handed coordinate system has been chosen such that the positive $x$-direction points seaward from the coast, and $y$-axis lies along the straight coastline at $x=0$ as in Fig. 1 . The depth distribution, $h(x)$, is given by

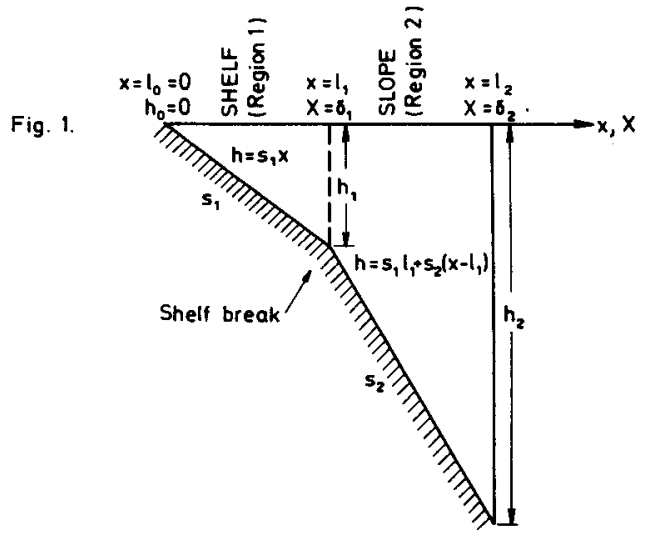

FIG. 1. Schematic diagram of the entire region encompassing both the continental shelf and slope which we refer to as the continental margin or margin. The total width is $l_{2}$ (nondimensional width $\delta_{2}$ ) with shelf width $l_{1}\left(\delta_{1}\right)$. The cross-shelf variables are $x$ (dimensional) and $X$ (nondimensional). The subscript $j$ refers to the shelf if $j=1$ or the slope if $j=2$. Oceanic forcing is applied at $x=l_{2}$ and wind forcing applies over the whole margin. The shelf break is the point where the shelf meets the slope at $x=l_{1}$.

$$
h= \begin{cases}s_{1} x, & 0 \leqslant x<l_{1} \\ h_{1}+s_{2}\left(x-l_{1}\right), & l_{1} \leqslant x \leqslant l_{2}\end{cases}
$$

where $h_{1}=s_{1} l_{1}$ and $h_{2}-h_{1}=s_{2}\left(l_{2}-l_{1}\right)$.

Following PMG we begin with the linearized, depthaveraged, shallow water equations for flow in a homogeneous, incompressible, barotropic and hydrostatic fluid forced by an alongshore wind stress $\tau$ which does not vary in a direction perpendicular to the coast. These equations are

$$
\begin{gathered}
f v=g \zeta_{x} \\
v_{t}+f u=-g \zeta_{y}-r v / h+\tau / \rho h \\
(h u)_{x}+(h v)_{y}=0
\end{gathered}
$$

where $u$ and $v$ are the horizontal, depth-averaged velocity components in the $x, y$ directions respectively; $t$ is time; $\zeta$ is the surface displacement, $g$ is the acceleration due to gravity; $f$ is the Coriolis parameter, (assumed constant); $\rho$ the density and subscripts denote partial differentiation.

Bottom friction has been assumed to be proportional to the depth-averaged velocity with a constant friction coefficient $r$. Only large-scale, subinertial and nondivergent motions are considered so that the terms $\partial u$ / $\partial t$ and $-r u / h$ in the cross-shelf momentum equation and $-\zeta_{t}$ in the continuity of mass equation have been omitted. These three equations have been presented by earlier workers in investigations of the evolution of the coastal boundary in response to an impulsive wind stress (for example, Birchfield and Lunde 1978; Maeland 1983). 
The equations are used to investigate three cases of coastal circulation which have different alongshore forcing mechanisms: 1) wind stress and either 2) oceanic pressure gradients or 3 ) oceanic currents imposed at the edge of the continental margin. Csanady (1978) investigated case 1 but restricted his attention to steady forcing and an inclined beach model. Middleton (1987) did the same for case 2 but also considered a parabolic depth profile.

Elimination of $u$ and $v$ from (2.2)-(2.4) yields the following equation for the surface displacement, $\zeta$ :

$$
h_{x} \zeta_{x t}+h \zeta_{x x t}+f h_{x} \zeta_{y}+r \zeta_{x x}=0
$$

This equation has been solved for an inclined beach by PMG (all three cases) and Thompson (1987) (case 1 , but with $\zeta=0$ at the shelf break only). The inviscid form of (2.5) was first solved by Robinson (1964), when he first coined the term "continental shelf wave." Robinson's pioneering work was later extended in a number of ways by Mysak (1967), but again, bottom friction was neglected. Denbo and Allen (1983) solved (2.5) analytically for forcing which does not vary in the longshore direction.

Equation (2.5) is in fact an equation for the vorticity of the integrated mass flux, $\pi$, since $\pi=(h v)_{x}-(h u)_{y}$ $\approx(h v)_{x}$ for the coastal ocean (for which alongshore scales are much greater than those across the margin) and so (2.5) can be rewritten as

$$
\pi_{t}+g h_{x} \zeta_{y}+\frac{r g}{f} \zeta_{x x}=0 .
$$

Thus the local rate of change of $\pi$ is due to vortex stretching across isobaths and the curl of the bottom stress.

In each case the coastal boundary condition is that of no normal transport, i.e.,

$$
h u \rightarrow 0 \text { as } x \rightarrow 0 .
$$

It follows from (2.2), (2.3) and (2.7) that

$$
\frac{\tau}{\rho}-r v \rightarrow g h\left(\frac{\zeta_{x t}}{f}+\zeta_{y}\right) \text { as } x \rightarrow 0,
$$

where the right-hand side is zero once it has been established that $\zeta$ and $\zeta_{x}$ are finite as $x \rightarrow 0$, since, in this model it is assumed that $h \rightarrow 0$ as $x \rightarrow 0$. Note that $\tau(x, y, t)$ is nonzero for case 1 only. If it is assumed that the wind stress propagates alongshore then we can write

$$
\tau(y, t)=\tau_{0} \exp [i(k y-\omega t)] .
$$

Consequently we consider a single Fourier component of the forcing function for which the response is given by

$$
\begin{aligned}
{[u, v, \zeta]=\operatorname{Re}\{[U(x),} & V(x), \bar{\zeta} \eta(x)] \\
& \times \exp [i(k y-\omega t)]\},
\end{aligned}
$$

where $k$ is the wavenumber and $\omega$ is the frequency (allowed to take either sign) of both the forcing and the response and $\bar{\zeta}$ is the amplitude of the surface displacement. Solutions for realistic forcing may be found by summing contributions from appropriate frequencies, but considerable insight into the dynamics is obtained here by considering a single, arbitrary component. Continuity of pressure and across-shelf transport are imposed at the shelf break. (Since $h$ is continuous there it will suffice to constrain the alongshore transport to be continuous in place of the condition on the transport across the shelf.)

The offshore boundary conditions can be readily stipulated in terms of dimensionless variables and their formulation is best left until after the general solution has been obtained in the following section.

\section{General solution, boundary and continuity conditions}

\section{a. Surface displacement}

The substitution of (2.1) and (2.10) into (2.5) gives

$$
\begin{aligned}
\left(1-\frac{i \omega h}{r}\right) \frac{d^{2} \eta_{j}}{d x^{2}}-\frac{i \omega s_{j}}{r} \frac{d \eta_{j}}{d x}+\frac{i k f s_{j}}{r} \eta_{j} & =0, \\
j & =1,2,
\end{aligned}
$$

where the subscript $j$ refers to either the shelf $(j=1)$ or the slope $(j=2)$. Transforming $x$ to dimensionless form using

$$
X= \begin{cases}h / s_{1} L, & 0 \leqslant x \leqslant l_{1} \\ h / s_{2} L, & l_{1}<x \leqslant l_{2},\end{cases}
$$

where the length scale $L$ is $1 / k$, reduces (3.1) to

$$
\left[\left(\Omega X+i \epsilon_{j}\right) \eta_{j}^{\prime}\right]^{\prime}-\eta_{j}=0,
$$

where the derivative is with respect to $X$. Here $\Omega=\omega /$ $f$ and $\epsilon_{j}=r /\left(f_{s_{j}} L\right)$. Setting $\xi_{j}(X)=2\left(\Omega X+i \epsilon_{j}\right)^{1 / 2} /$ $\Omega$ reduces $(3.3)$ to

$$
\xi_{j} \eta_{j}^{\prime \prime}+\eta_{j}^{\prime}-\xi_{j} \eta_{j}=0 .
$$

The derivatives are now with respect to the complex variables $\xi$ with the appropriate subscript. The choice of the branch for $\xi$ has $\operatorname{Re}\{\xi\}>0$. For real $\Omega, \xi$ $=2(\Omega X+i \epsilon)^{1 / 2} / \Omega$ is confined to the hyperbola $\alpha \beta$ $=2 \epsilon /|\Omega|$. A complete analysis of $\xi(X)$ as $X$ increases from zero can be found in PMG.

Equation (3.4) is the modified Bessel equation of order zero and has linearly independent solutions $I_{0}$ and $K_{0}$, the modified Bessel functions of the first and third kinds, respectively. Thus

$$
\eta_{j}\left(\xi_{j}\right)=A_{j} I_{0}\left(\xi_{j}\right)+B_{j} K_{0}\left(\xi_{j}\right) .
$$

The complex constants $A_{j}$ and $B_{j}$ have values governed by the boundary and continuity conditions imposed in section $3 \mathrm{c}$.

The complex functions $I_{m}$, were calculated using International Mathematical (IMSL) subroutine 
DCBINS. The $K_{m}$ were calculated from various formulae taken from Abramowitz and Stegun (1965).

\section{b. Transport}

We now introduce a scaled, dimensionless volume transport, $\hat{\mathbf{U}}=(\hat{U}, \hat{V})$, where the alongshore component, $\hat{V}_{j}=s_{j} X d \eta_{j} / d X$ is given by

$$
\begin{aligned}
& \hat{V}_{j}(X)=2 s_{j} X\left(A_{j} I_{1}-B_{j} K_{1}\right) / \Omega \xi_{j}(X) \\
& \hat{U}_{j}(X)=\left(i \Omega-\epsilon_{j} / X\right) \hat{V}_{j}-i s_{j} X \eta_{j}+\hat{\tau} \epsilon_{j},
\end{aligned}
$$

where $\hat{\tau}=1$ in case 1 , zero otherwise.

\section{c. Boundary and continuity conditions}

\section{1) THE COASTAL BOUNDARY CONDITIONS}

Elimination of $v(0)$ from the nondimensional form of $(2.8)$ and $(2.10)$ gives

$$
\frac{d \eta_{1}}{d X} \rightarrow 1 \quad \text { as } \quad X \rightarrow 0
$$

in case 1 if $\bar{\zeta}$ is defined by $\bar{\zeta}=\bar{\tau} f L / \rho \mathrm{r} g$.

In cases 2 and 3

$$
\frac{d \eta_{1}}{d X} \rightarrow 0 \quad \text { as } \quad X \rightarrow 0
$$

\section{2) THE CONTINUITY CONDITIONS}

The variables $h u$ and $\zeta$ must be continuous over the entire margin and, in particular, at the shelf break. This implies that

$$
\begin{aligned}
\eta_{1}\left(X=\delta_{1}\right) & =\eta_{2}\left(X=h_{1} / s_{1}\right) \\
\left.\frac{d \eta_{1}}{d X}\right|_{X=\delta_{1}} & =\left.\frac{d \eta_{2}}{d X}\right|_{X=h_{1} / s_{2} L} .
\end{aligned}
$$

\section{3) THE OFFSHORE BOUNDARY CONDITIONS}

In each case the solution is constrained at $x=l_{2}(X$ $=\delta_{2}$ ).
Gill and Schumann (1974) have shown that an appropriate offshore boundary condition for case 1 is

$$
V\left(\delta_{2}\right)=0
$$

which becomes

$$
\left.\frac{d \eta_{2}}{d X}\right|_{X=\delta_{2}}=0
$$

if it is assumed that a geostrophic balance exists at $X$ $=\delta_{2}$. This boundary condition is further discussed by PMG. In case $2, \zeta_{y}=P$ where $P=\bar{P} \exp [i(k y-\omega t)]$ is the alongshore, sea-level slope at $X=\delta_{2}$. Choosing $\bar{\zeta}=\bar{P} / k$ gives

$$
\eta_{2}\left(\delta_{2}\right)=-i \text {. }
$$

The condition in case 3 reduces to

$$
\left.\frac{d \eta_{2}}{d X}\right|_{X=\delta_{2}}=1
$$

if $\bar{\xi}=f \bar{V} L / g$.

The above boundary conditions, expressed in terms of $\xi_{j}$, are summarized in Table 1 . The coastal boundary condition is nonhomogeneous under wind forcing only. Each case has a different offshore boundary condition while the continuity conditions remain the same.

\begin{tabular}{|c|c|c|c|c|}
\hline Case & Forcing type & $\begin{array}{c}\text { Coastal boundary condition } \\
x=0, X=0 \\
\xi_{10}=\xi_{1}(0)\end{array}$ & $\begin{array}{c}\text { Continuity conditions } \\
x=l_{1}, \xi_{11}=\xi_{1}\left(\delta_{1}\right) \\
\xi_{20}=\xi_{2}\left(h_{1} / s_{2}\right)\end{array}$ & $\begin{array}{c}\text { Offshore boundary conditions } \\
x=l_{2}, X=\delta_{2}, \\
\xi_{21}=\xi_{2}\left(\delta_{2}\right)\end{array}$ \\
\hline 1 & Wind & $\frac{d \eta_{1}}{d \xi_{1}}=\left(i \epsilon_{1}\right)^{1 / 2}$ & $\eta_{1}\left(\xi_{1}\right)=\eta_{2}\left(\xi_{2}\right)$ & $\left.\frac{d \eta_{2}}{d \xi_{2}}\right|_{\xi_{21}}=0$ \\
\hline 2 & Oceanic APG & $\frac{d \eta_{1}}{d \xi_{1}}=0$ & $\left.\frac{1}{\xi_{1}} \frac{d \eta_{1}}{d \xi_{1}}\right|_{\xi_{11}}=\left.\frac{1}{\xi_{2}} \frac{d \eta_{2}}{d \xi_{2}}\right|_{\xi_{20}}$ & $\eta_{2}\left(\xi_{21}\right)=-i$ \\
\hline 3 & Oceanic current & & & $\left.\frac{d \eta_{2}}{d \xi_{2}}\right|_{\xi_{21}}=\frac{\Omega \xi_{21}}{2}$ \\
\hline
\end{tabular}

The various solutions are then obtained by expressing the equations in Table 1 in terms of the modified Bessel functions. In matrix form, $\mathbf{C A}=\mathbf{b}$, the relevant equations become

$$
\begin{aligned}
& {\left[\begin{array}{cccc}
I_{110} & -K_{110} & 0 & 0 \\
I_{011} & K_{011} & -I_{020} & -K_{020} \\
I_{111 / \xi_{11}} & -K_{111 / \xi_{11}} & -I_{120 / \xi_{20}} & K_{120 / \xi_{20}} \\
0 & 0 & I & K
\end{array}\right]} \\
& \times\left[\begin{array}{c}
A_{1} \\
B_{1} \\
A_{2} \\
B_{2}
\end{array}\right]=\left[\begin{array}{c}
b_{1} \\
0 \\
0 \\
b_{4}
\end{array}\right] .
\end{aligned}
$$

Here $I_{m n p}$ is the modified Bessel function of the first kind, order $m$, with argument $\xi_{n}(n=1$ over the shelf,

TABLE 1. Continuity and boundary conditions. 
$n=2$ over the slope) evaluated at the extreme left ( $p$ $=0)$ or at the extreme right $(p=1)$ of the region. For example, $I_{110}=I_{1}\left(\xi_{1}(X=0)\right)$ and $K_{111}=K_{1}\left(\xi_{1}(X\right.$ $\left.=\delta_{1}\right)$ ).

The elements $I$ and $K$ are $I_{121},-K_{121}$ in cases 1 and 3 , and $I_{021}, K_{021}$ in case 2. Here $K_{021}=K_{0}\left(\xi_{2}\left(\delta_{2}\right)\right)$ for example, where $\delta_{2}$ is the value of $X$ at the end of the margin.

The vector $\mathbf{b}$ determines the type of forcing and is therefore different in each case:

$$
\mathbf{b}=\left(\begin{array}{c}
\left(i \epsilon_{1}\right)^{1 / 2} \\
0 \\
0 \\
0
\end{array}\right),\left(\begin{array}{c}
0 \\
0 \\
0 \\
-i
\end{array}\right),\left(\begin{array}{c}
0 \\
0 \\
0 \\
\Omega \xi_{21} / 2
\end{array}\right)
$$

in cases 1,2 and 3 respectively.

The current forced solutions are not presented in the following section because there is a simple relationship between the solutions in cases 2 and 3 . The ratio of their surface displacements, $\gamma=\eta_{3} / \eta_{2}$, is given by

$$
\gamma=\frac{\left(\Omega \delta_{2}+i \epsilon_{2}\right) I_{021}}{\Omega\left(B_{2 p}-i I_{121}\right)}
$$

where $B_{2 p}$ is the value of $B_{2}$ in case 2. PMG have shown that if $s_{1}=s_{2}=s$ then

$$
\gamma \sim i\left(\frac{\omega s l_{2}}{r}+i\right)^{1 / 2}
$$

for large $l_{2}$.

The constants $A_{j}$ and $B_{j}$ can now be readily obtained. (A presentation of their precise algebraic form would not provide any insight into the problem and is therefore omitted). Once the constants have been determined, equations (3.6) and (3.7) can then be used to calculate the dimensionless, scaled transport $\hat{\mathbf{U}}$ $=(\hat{U}, \hat{V})$.

\section{d. A description of the forced response}

In Figs. 3-10 either one of the groups of profiles depicted in Fig. 2 are considered. The profiles are used to investigate the importance of the parameter $s_{1} / s_{2}$ (Fig. 2a) or $h_{1}$ (Fig. 2b) in the forced response with all other independent parameters fixed. All figures have $r$ $=5.0 \times 10^{-4} \mathrm{~m} \mathrm{~s}^{-1}, f=10^{-4} \mathrm{~s}^{-1}$ and $k=2 \pi /(2000$ $\mathrm{km})$ unless otherwise stated. A number of their important features are summarized in Table 2. The dynamical variables are all scaled in both the plots and Table 2. For the figures corresponding to wind-forcing, $\zeta$ is in units of $\bar{\tau} / \rho f\left(\approx 10^{-4} \mathrm{~m}\right.$, if $\left.\bar{\tau}=0.1 \mathrm{~N} \mathrm{~m}^{-2}\right), v$ in $g k \bar{\tau} / \rho f\left(\approx \pi \times 10^{-5} \mathrm{~m} \mathrm{~s}^{-1}\right)$ and transport per unit width in $g \tau / \rho f\left(\approx 0.1 \mathrm{~m}^{2} \mathrm{~s}^{-1}\right)$. The equivalent parameter groups for the figures corresponding to APG forcing are $\bar{P} / k$ for $\zeta(\approx 1 / 2 \pi$ if $\bar{P}=1.0 \mathrm{~m} /(2000 \mathrm{~km}))$, $g \bar{P} / f$ for $v\left(\approx 0.05 \mathrm{~m} \mathrm{~s}^{-1}\right)$ and $g \bar{P} / k f\left(\approx 5 / \pi \times 10^{+4}\right.$ $\left.\mathrm{m}^{2} \mathrm{~s}^{-1}\right)$ for the transport per unit width. In the table
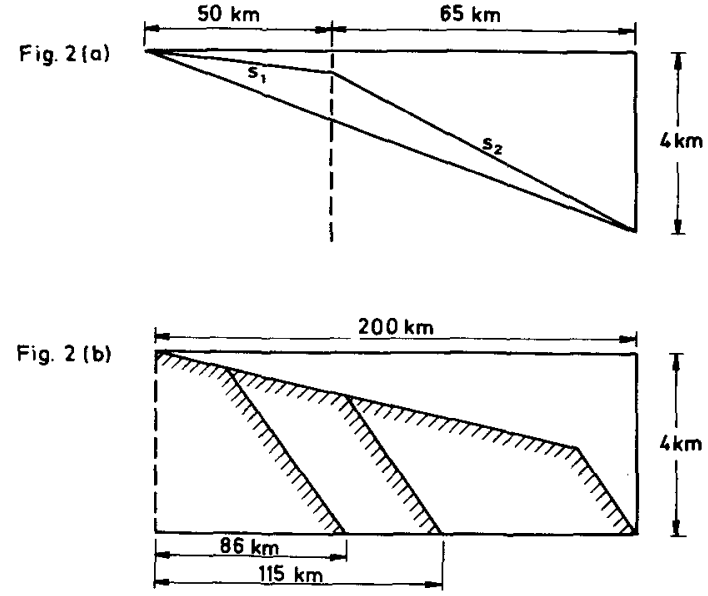

Flg. 2. Schematic diagrams of the continental margin used in section 3d. In (a) $l_{1}$ and $l_{2}$ are fixed with $s_{1}$ and $s_{2}$ allowed to vary. In (b) $s_{1}$ and $s_{2}$ are fixed but $h_{1}$, the depth at the shelf break, is allowed to vary. In both (a) and (b) the depth of the ocean at the edge of the margin is fixed at $4 \mathrm{~km}$.

the geometry of the margin, the frequency of the forcing, the real part of the modal frequencies (modes 1 and 2 only), the scaled values of the maxima of the dynamical variables and the approximate position at which they occur, are all given.

\section{1) CASE 1, CIRCULATION DRIVEN BY WIND}

The forced response to wind forcing on two different margins is considered at the frequency of the winddriven band, first for forcing moving in the opposite direction to free mode propagation (see section 4 ) in Fig. $3(\Omega=\omega / f=0.3)$ and then in the same direction (Fig. $4, \Omega=-0.3$ ). The forcing function propagates with the coast on its left if $\Omega>0$. In both figures the surface displacement (a) and longshore velocity (b) are presented. The results for a margin with constant slope is on the left, while a margin with $s_{1} \ll s_{2}$ is considered on the right. In all plots, the ocean depth is approximately $4 \mathrm{~km}$. In this and subsequent diagrams, the graphs set in the contour plots of the surface displacement show the response of the margin under consideration as a function of forcing frequency (from $\Omega$ $=-0.4$ up to $\Omega=+0.4$ ). The response here is in fact the amplitude of the surface displacement at a midshelf location. The graphs set in the contour plots of longshore velocity, on the other hand, show the structure of the transport across the margin.

When $\Omega=0.3$ and $s_{1}=s_{2}$, significant surface displacements, $\zeta$, and longshore velocities, $v$, are trapped in a nearshore band as in Csanady's (1978) arrested topographic wave solution. When $s_{1} \ll s_{2}$, however, significant $\zeta$ and $v$ are found over the entire shelf due to the reduction in the volume of water overlying it, but do not extend beyond the shelf break. Maximum transports (inset) have shifted from a position near the 


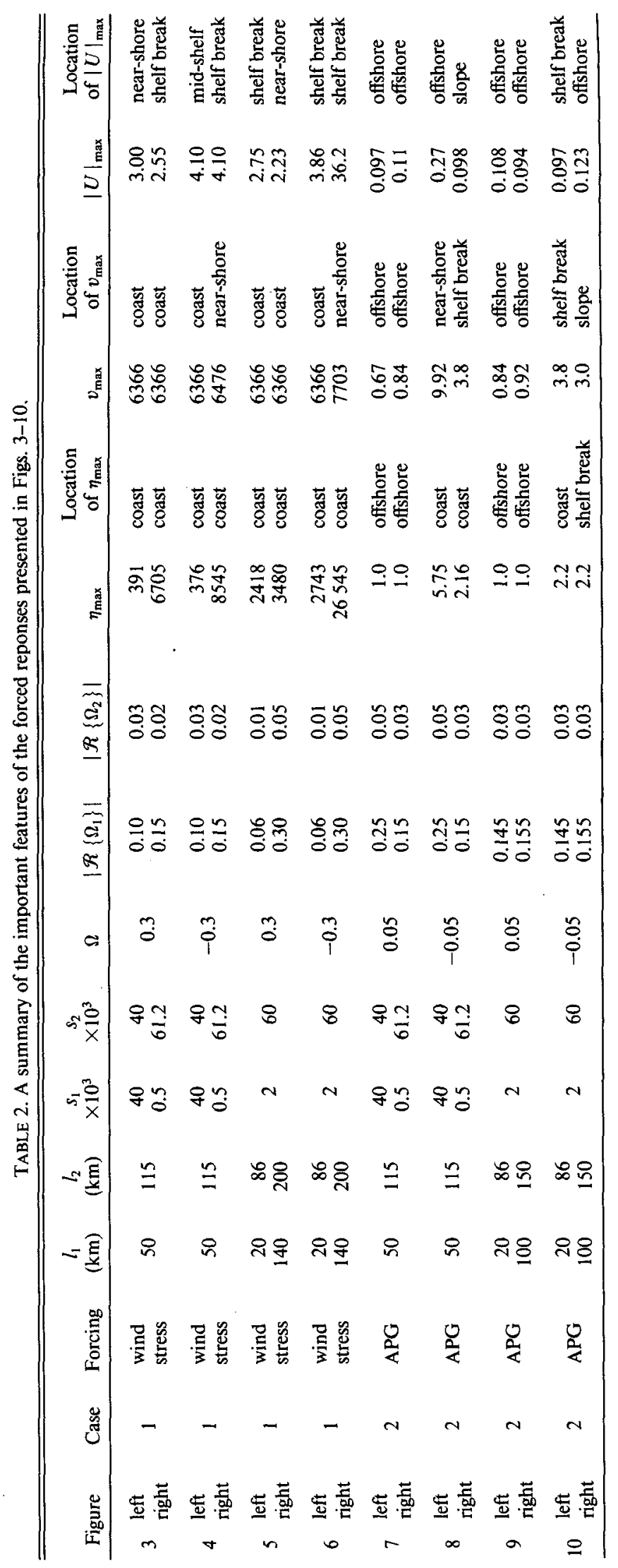



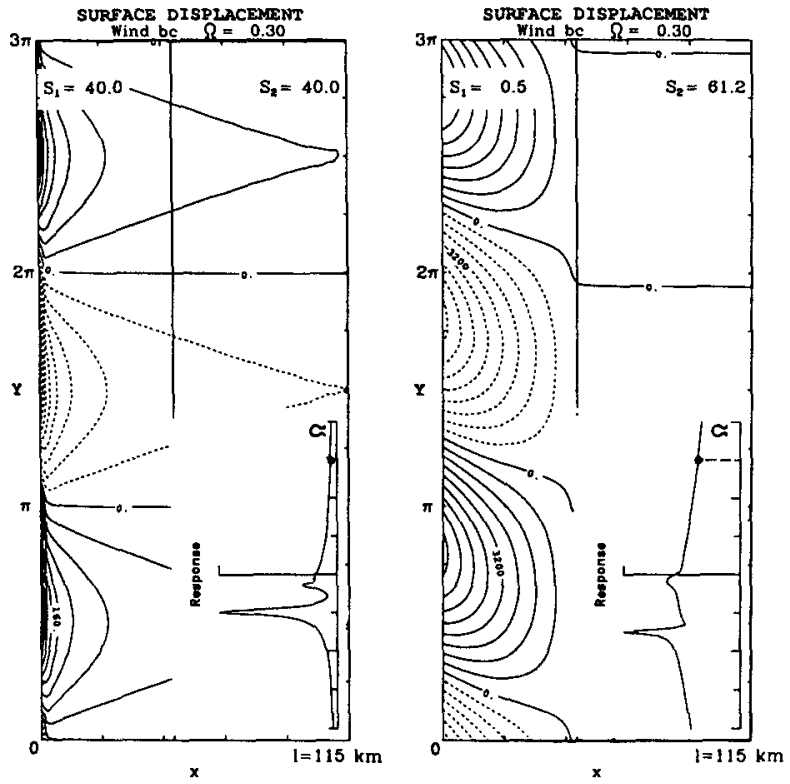

the coast on both margins. These results are little changed at reduced frequencies, even at $\Omega \approx 0$ (which corresponds to the steady, arrested topographic wave), when the forcing function does not propagate. This is in stark contrast to the results when $\Omega=-0.3$ in Fig. 4. When $s_{1}=s_{2}$ (on the left) significant $\zeta$ are found over the entire margin, while $v$ is trapped nearshore, by a distance significantly less than the width of the shelf. When $s_{1} \ll s_{2}$, on the other hand, the solution is virtually the same as if $\zeta$ were set to zero along the
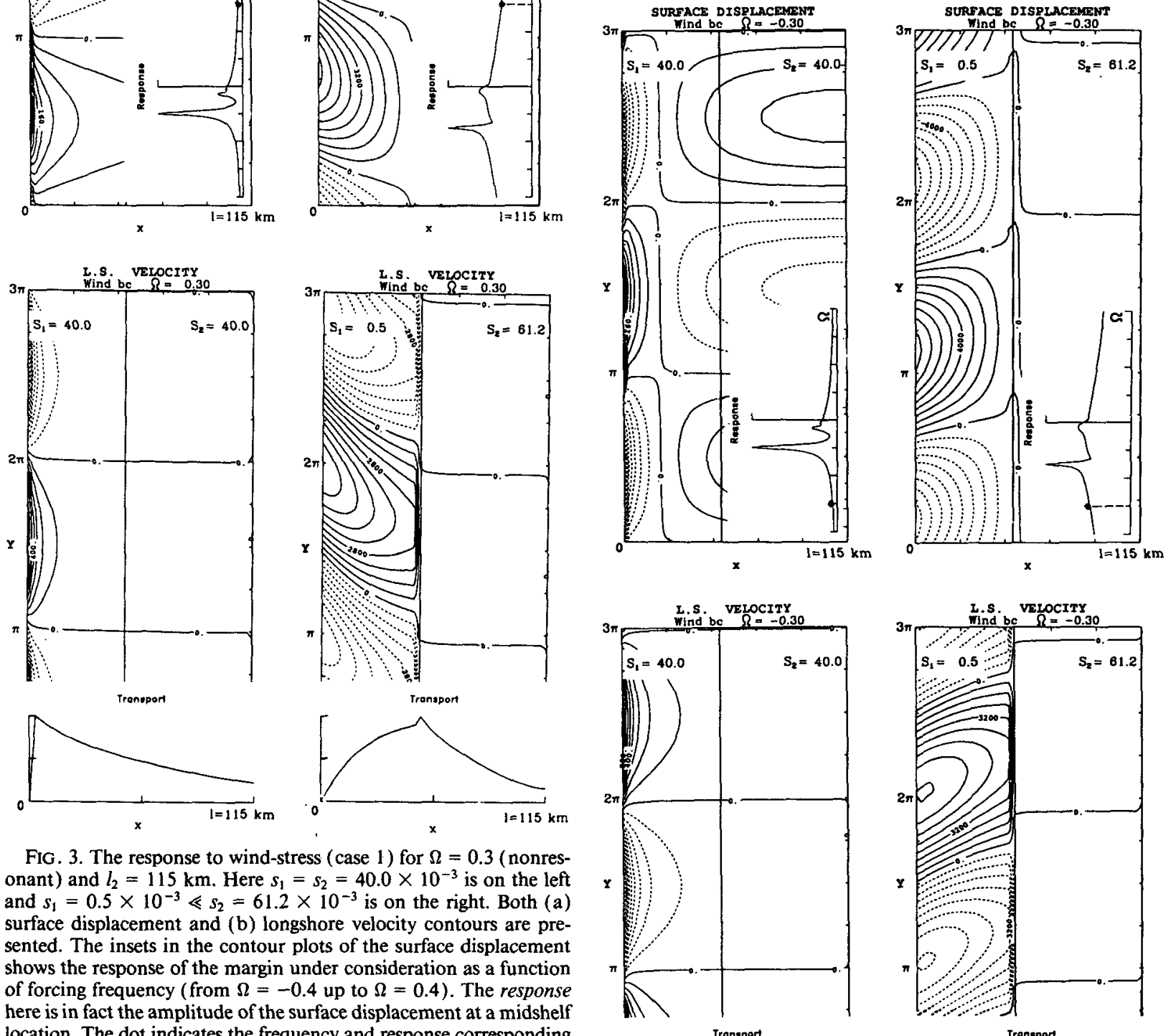
here is in fact the amplitude of the surface displacement at a midshelf location. The dot indicates the frequency and response corresponding to the situation depicted in the contour plot. The insets in the contour plots of the longshore velocity, on the other hand, show the structure of the transport across the margin for precisely the same parameter values used in the contour plot in which it is set.

shore to the shelf break. Phase shifts across the shelf are more important due to the increase in frictional effects. Maximum amplitudes of $\zeta$ and $v$ are located at
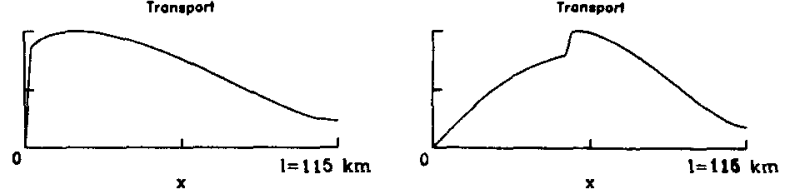

FIG. 4. The response to wind-stress when $\Omega=-0.3$ whereby the forcing function moves in the same direction as free modes propagate. All other parameter values are the same as those in Fig. 3. 
shelf break. Maximum transports now occur over the middle of the shelf on both margins. As expected, nearshore leads offshore in phase. There is little phase change across the slope $(\Delta \phi \approx 0)$. The horizontal shear evident on the shelf near the shelf break when $s_{1} \ll s_{2}$ would be reduced if the transition from the shelf to the slope occurred over a finite distance rather than at a point as we have assumed here. Typically, however, this transition zone has a width which is small compared with the width of either the shelf or the slope and so we expect such shear to be a genuine feature of the coastal ocean despite the fact that its magnitude is probably overestimated here.
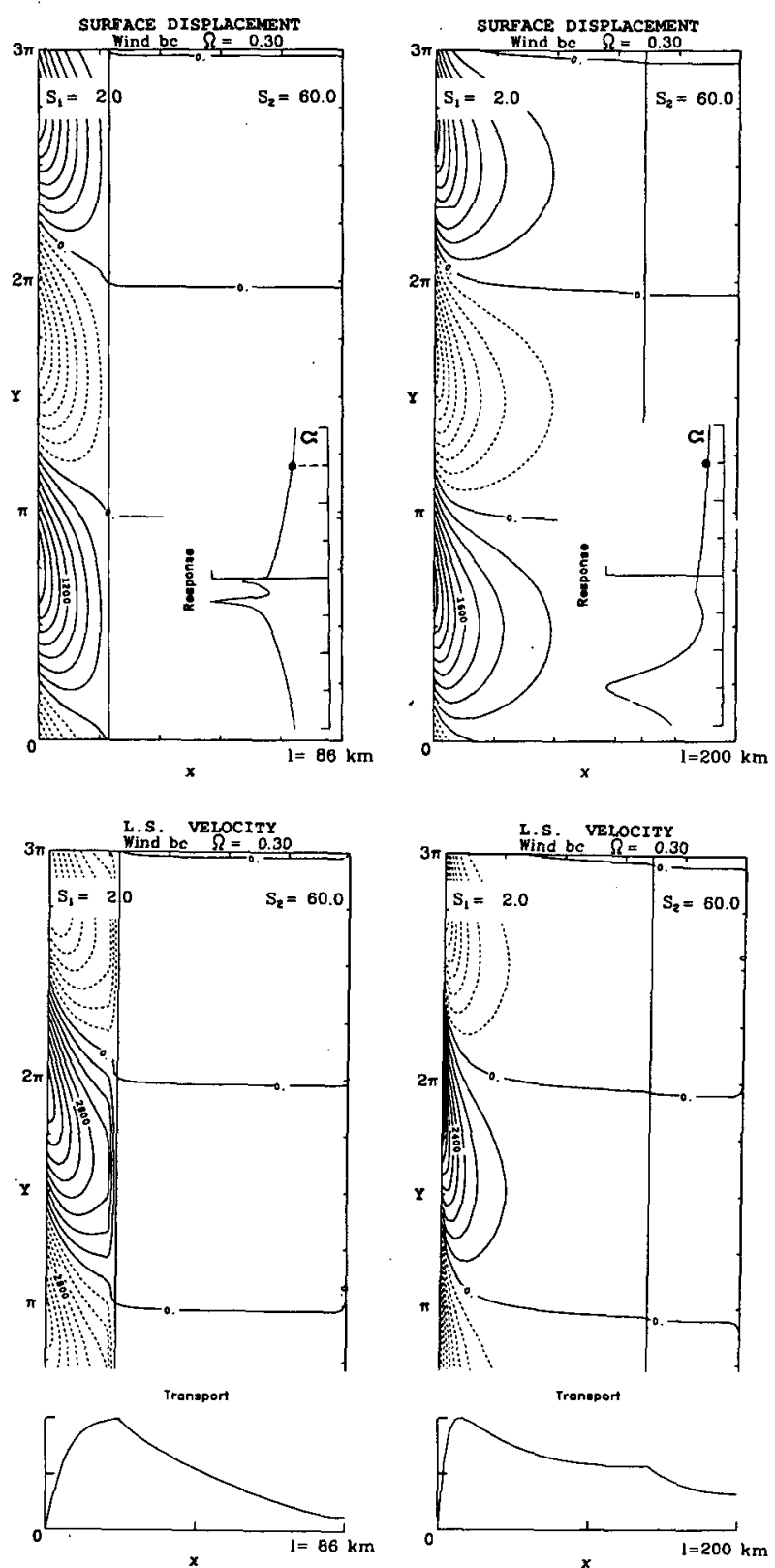

In Figs. 5 and 6, the importance of margin width in determining the structure of the solution is illustrated. When $\Omega=0.3$ (Fig. 5) the results remain similar on margins with widths ranging from 86 up to $200 \mathrm{~km}$. In each case $s_{1}, s_{2}$ and the ocean depth are fixed at $0.002,0.06$ and $4 \mathrm{~km}$, respectively. The wind generates a pressure response which is trapped nearshore. If the shelf break occurs within this trapping length then the shelf width becomes the effective trapping length. Again the nearshore response leads that offshore in phase $(\Delta \phi$ $>0$ ). In Fig. $5 c$, the transport streamfunction is contoured. The transport between contours is the same. Note that the longshore scale has been substantially
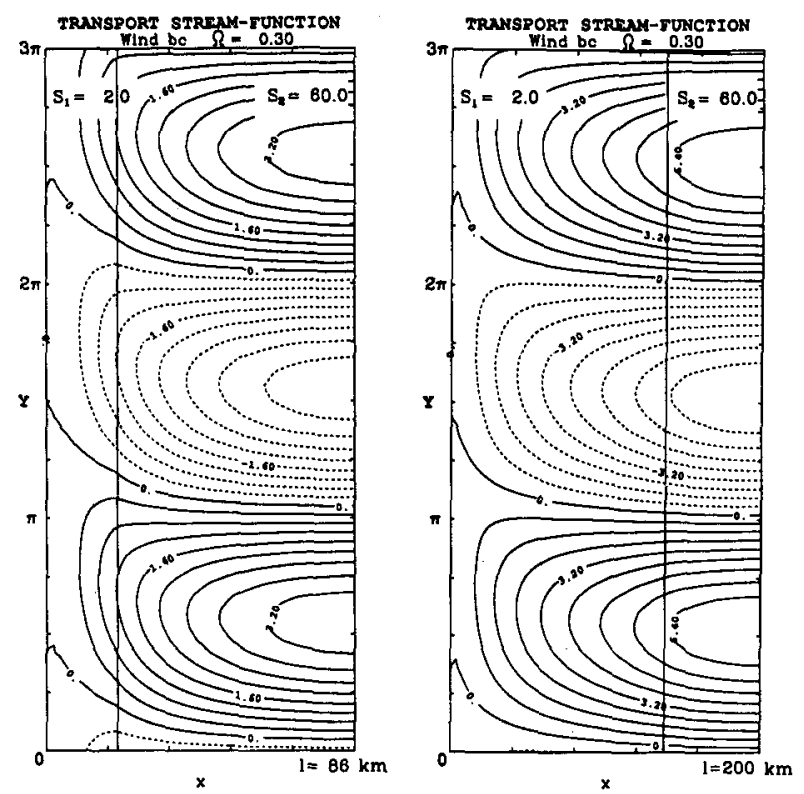

FIG. 5. The response to wind-stress forcing (case 1) for $\Omega=0.3$ (nonresonant) and fixed $s_{1}=2.0 \times 10^{-3}$ and $s_{2}=60.0 \times 10^{-3}$ but with the shelf and margin widths varying: $I_{2}=86 \mathrm{~km}$ (left) and 200 $\mathrm{km}$ (right). (a) Surface displacement, (b) longshore velocity and (c) transport contours are presented. Again the insets to the $\zeta$ plots are of response versus frequency $(\Omega=-0.4$ to $\Omega=0.4$ ) while those in the $v$ plots show the structure of the transport across the margin. 

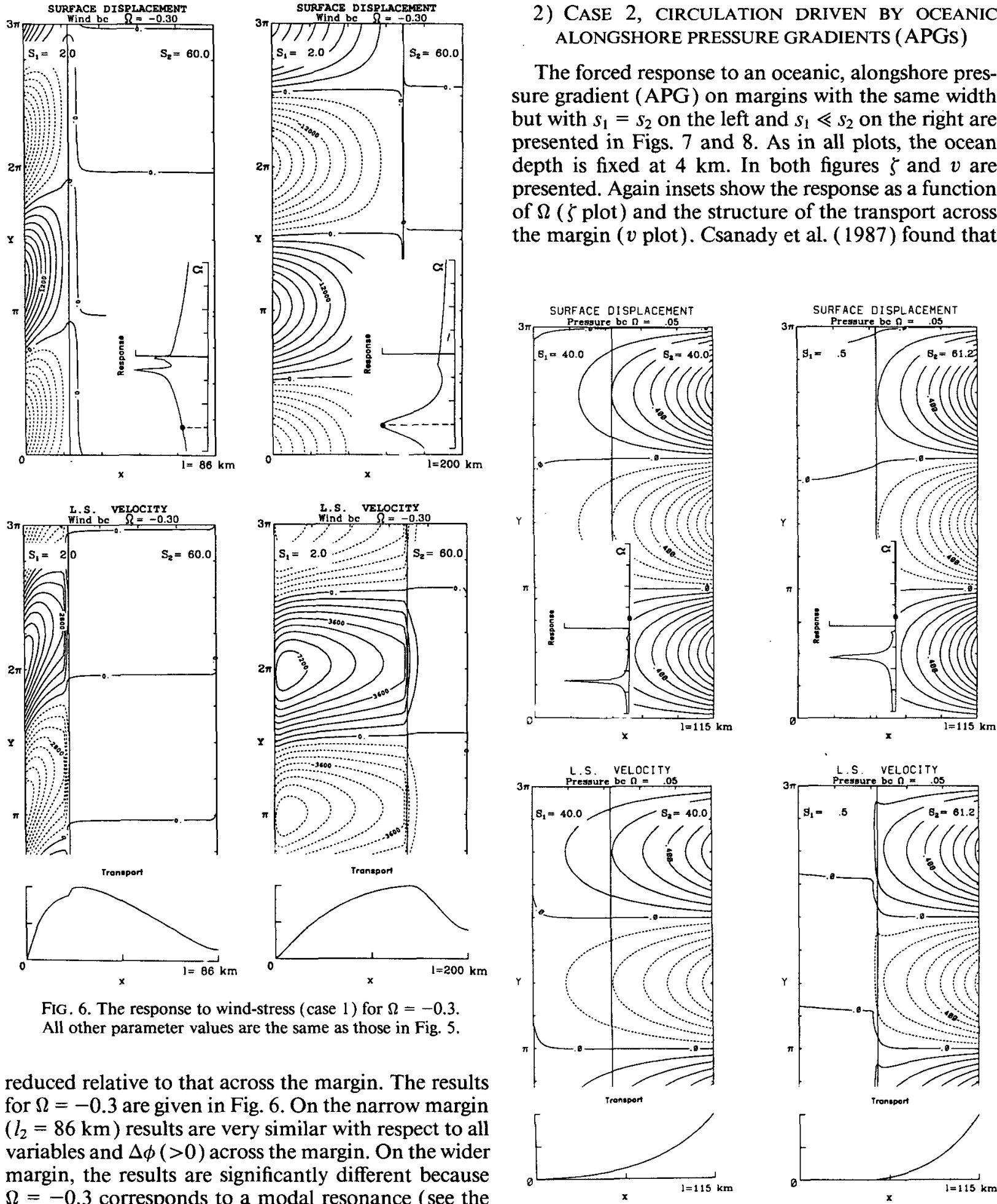

FiG. 7. The response to an offshore, oceanic pressure gradient (case 2) for $\Omega=0.05$ and $l_{2}=115 \mathrm{~km}$. Here $s_{1}=s_{2}=40.0 \times 10^{-3}$ is on the left and $s_{1}=0.5 \times 10^{-3} \ll s_{2}=61.2 \times 10^{-3}$ is on the right. Both (a) surface displacement and (b) longshore velocity contours are presented. Again the insets to the $\zeta$ plots show the response as a function of forcing frequency $(\Omega=-0.4$ to $\Omega=0.4)$ while those in the $v$ plots show the structure of the transport across the margin. 

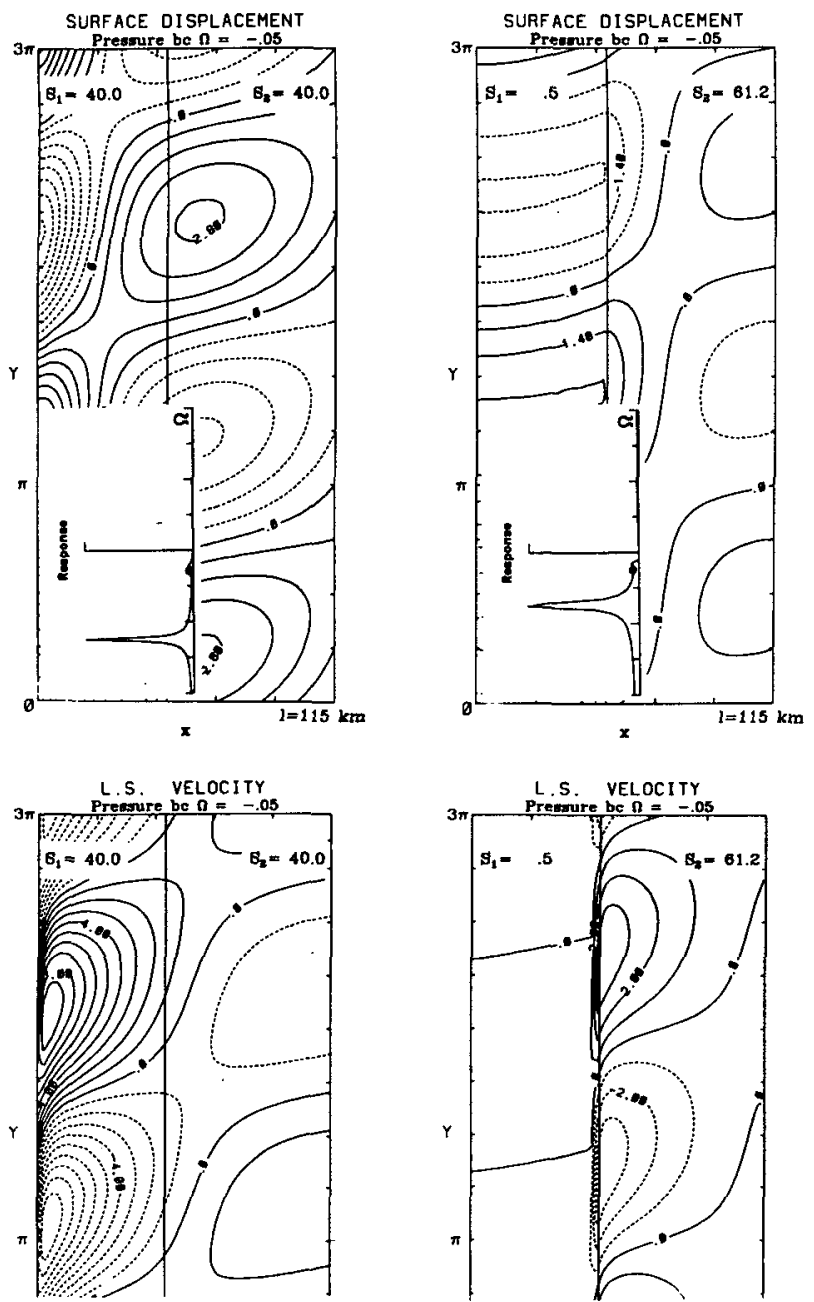

Trontport
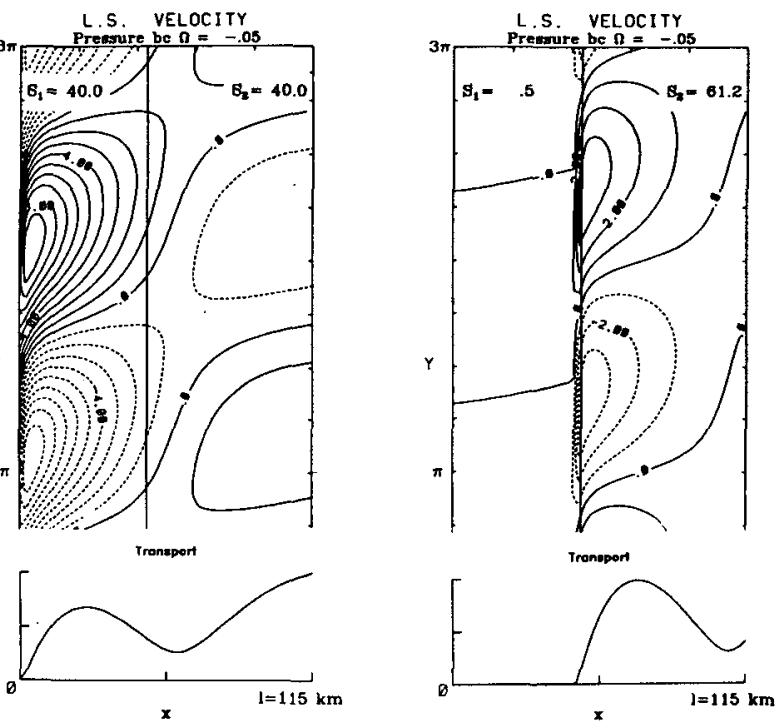

FIG. 8. The response to an offshore, oceanic pressure gradient (case 2) for $\Omega=-0.05$. All other parameter values are the same as those in Fig. 7.

most of the variance in long-term currents observed over the slope in the Mid-Atlantic Bight occur at very low frequencies $(\Omega \leqslant 0.05$ ). We therefore choose $\Omega$ $= \pm 0.05$ but note that the model is applicable for any frequency which satisfies $\Omega^{2} \ll 1$. The results when $\Omega$ $=0.05$ (Fig. 7) are remarkably similar on the two margins. Maxima in $\zeta,|\hat{\mathbf{U}}|$ (the transport) and $v$ occur at the ocean boundary. There is very little phase difference across the margin in $\zeta$. This is also true for $|\hat{\mathbf{U}}|$ and $v$ except over the shelf where coastal positions lead positions at the shelf break. When $\Omega=-0.05$ (Fig. 8) $\zeta$ is similar on both margins but substantially different to the $\Omega=+0.05$ results. Maximum $\zeta$ are now at the coast with secondary maxima on the slope near the shelf break. The structure of both $v$ and $|\hat{\mathbf{U}}|$ are also dramatically altered on both margins. If $s_{1}=s_{2}$ (on the left) $v$ has a maximum and $|\tilde{\mathbf{U}}|$ has a significant secondary maximum near the coast. If $s_{1} \ll s_{2}$ (on the right) $v$ is greatest near the shelf break while $|\hat{\mathbf{U}}|$ is now greatest over the slope nearby. The inset to the $\zeta$ plots indicates that $\Omega=-0.05$ is near a secondary resonance.

The next group of forced solutions presented illustrate the importance of margin width in the APG forced
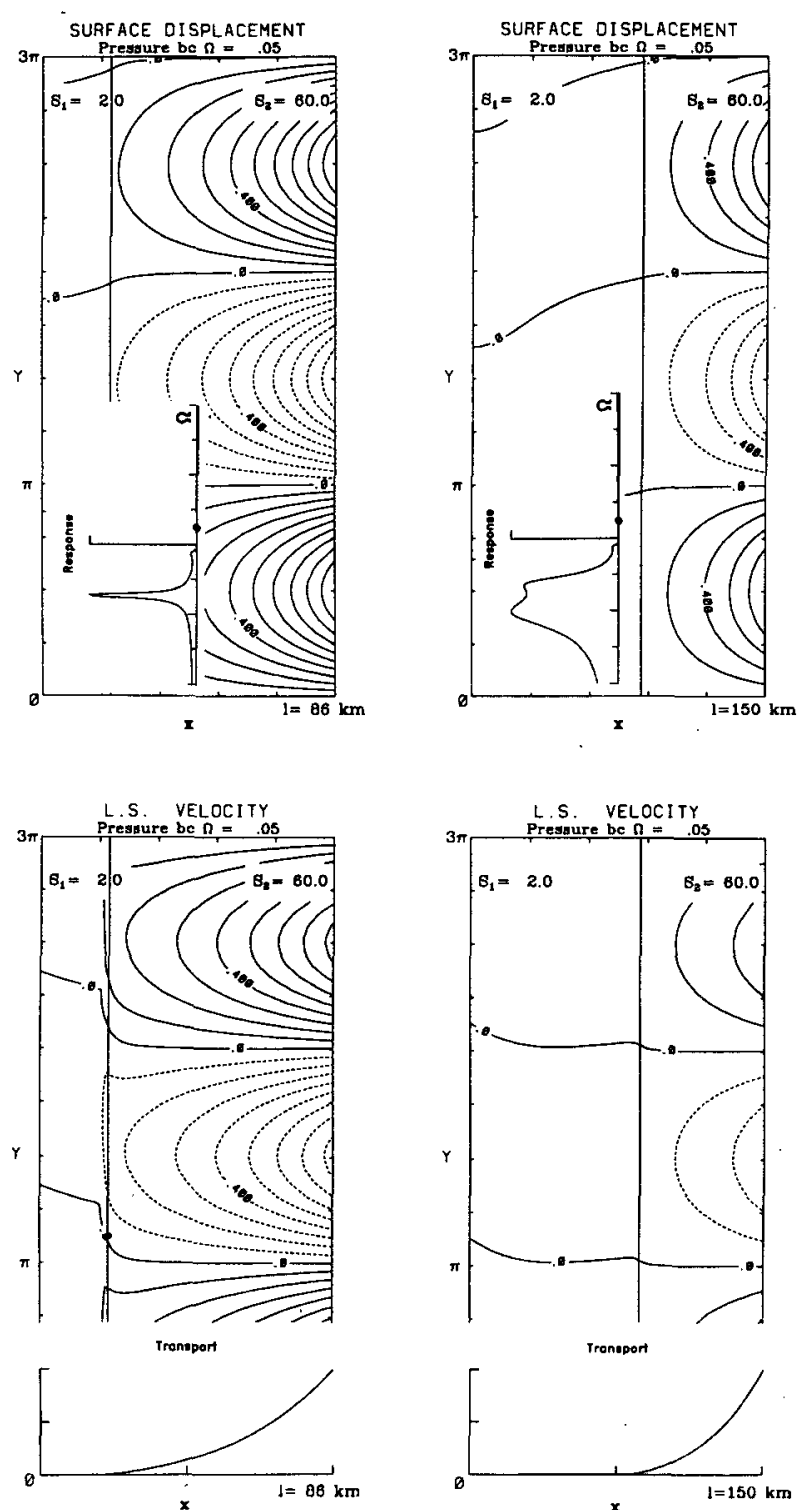

FIG. 9. The response to an offshore, oceanic pressure gradient (case 2) for fixed $s_{1}=2.0 \times 10^{-3}$ and $s_{2}=60.0 \times 10^{-3}$ but with the shelf and margin widths varying with $l_{2}=86 \mathrm{~km}$ on the left and $l_{2}=150$ km on the right. (a) Surface displacement and (b) longshore velocity are presented. The contour interval in (b) is the same for both plots $(0.1)$. 
solutions. For $\Omega=0.05$ (Fig. 9) the results are little changed for widths from $86 \mathrm{~km}$ up to $150 \mathrm{~km}$. Maximum $\zeta,|\hat{\mathbf{U}}|$ and $v$ occur at the ocean boundary, $\Delta \phi$ is small but with small differences across the near-shore and shelf break regions. When $\Omega=-0.05$ (Fig. 10), results are markedly different due to the fact that both responses are now nearly resonant (see the inset to the $\zeta$ plots $)$. On the narrow margin $\left(l_{2}=86 \mathrm{~km}\right.$, on the left) the resonant peak is the smallest of two, while on the wider margin $\left(l_{2}=150 \mathrm{~km}\right.$, on the right $)$ it is the smallest of three. The narrow margin has maximum $\zeta$ at the coast with secondary maxima over the outer slope. Maximum longshore velocities and transport (set
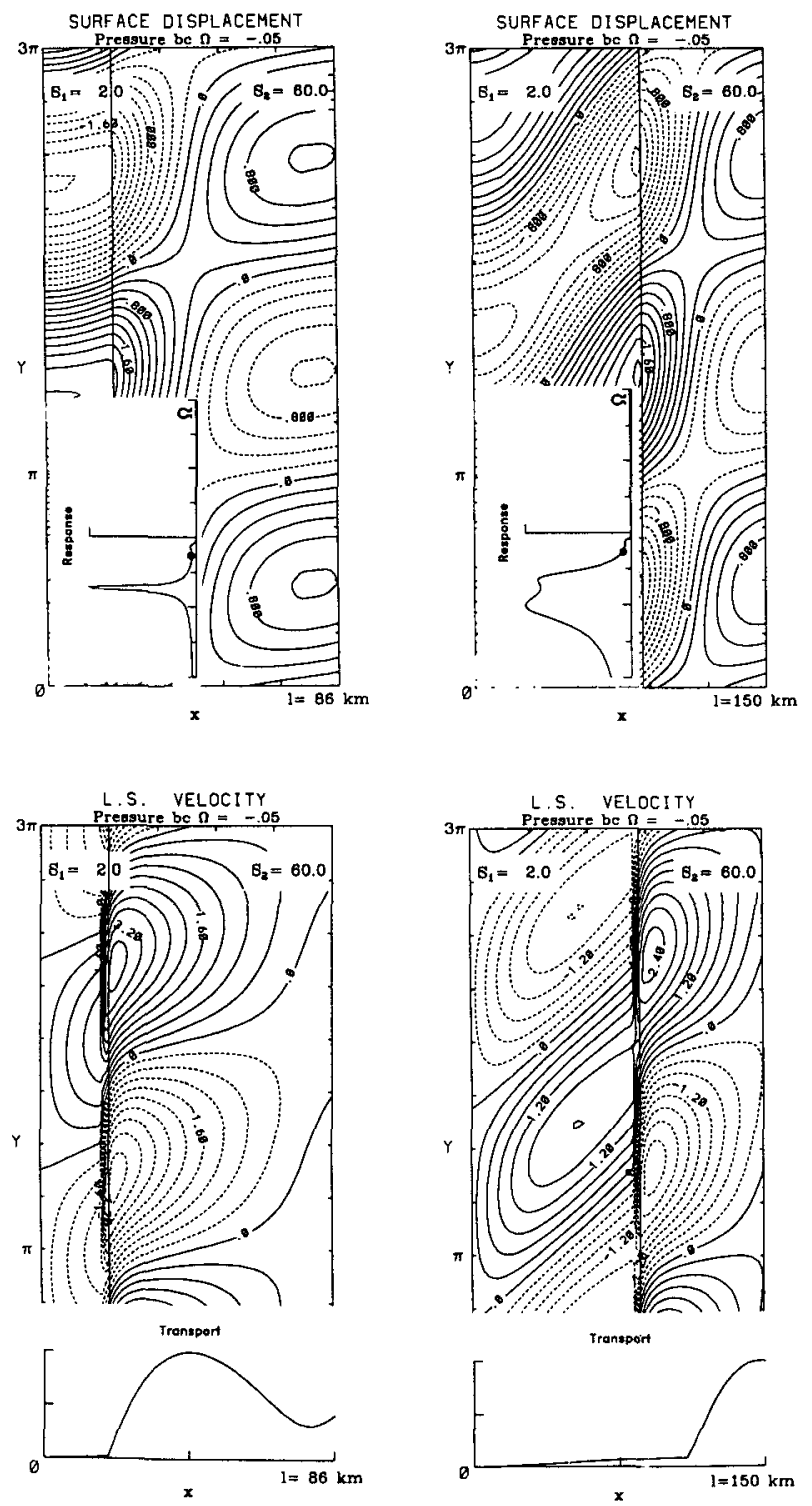

FIG. 10. The response to an offshore, oceanic pressure gradient (case 2) for $\Omega=-0.05$. All other parameter values are the same as those in Fig. 9. in $v$ plots) occur on the slope near the shelf break. The widest margin has maximum $\zeta$ near the shelf break with secondary maxima at the coast and offshore. Transports diminish monotonically from a maximum offshore.

The last forced solutions presented (Fig. 11) show the amplitude of the surface displacement at a midshelf location for frequencies, $\Omega$, between -0.4 and +0.4 . The three curves correspond to three different values of $r: 1.0 \times 10^{-4} \mathrm{~m} \mathrm{~s}^{-1}$, (solid) $5.0 \times 10^{-4} \mathrm{~m} \mathrm{~s}^{-1}$ (broken) and $10.0 \times 10^{-4} \mathrm{~m} \mathrm{~s}^{-1}$ (dashed). On the left are the results for wind forcing while on the right the results are for forcing by an APG. In both cases increased bottom friction reduces the response at resonance, broadens the peaks and detunes, or shifts, the resonant peaks to slightly lower frequencies. One interesting feature of the response to forcing by an APG is the strong dependence it has upon the direction in which the forcing moves: when $\Omega \geqslant 0$ the amplitude is far less than when $\Omega<0$. (Contrast this with the windforced solutions whose amplitudes remain of a comparable size at all the frequencies considered if $r \geqslant 5.0$ $\times 10^{-4} \mathrm{~m} \mathrm{~s}^{-1}$.) This result is common to all the margins considered in this paper and would therefore appear to be quite a general result. This means that the amplitude of the shelf circulation driven by offshore forcing could be greatly underestimated and its structure misrepresented if a steady model were employed and the forcing actually moves in the direction of shelf wave propagation. The speed of the forcing does not have to be great for the steady model to become inappropriate. In fact for the margin considered $\left(s_{1}=2.0\right.$ $\times 10^{-3}, s_{2}=76.0 \times 10^{-3}, l_{1}=100 \mathrm{~km}, l_{2}=150 \mathrm{~km}$ ) a mode 3 resonance occurs when $\Omega$ is only -0.02 which corresponds to a phase speed of only $0.6 \mathrm{~m} \mathrm{~s}^{-1}$ if $k$ $=2 \pi /(2000 \mathrm{~km})$.

As can be seen by the maximum values of the dynamical variables given in Table 2 the wind-forced solutions have amplitudes which are typically greater than those of the solutions forced by APGs for the frequencies considered (i.e., $\Omega= \pm 0.3 \Omega= \pm 0.05$ for the solutions forced by wind stress and APGs, respectively). However, this result will certainly not be true at all frequencies, on all margins, since it is conceivable that on some margins during certain periods the wind forcing will not excite free modes but the APGs will. Also, the rather arbitrary value of $1.0 \mathrm{~m} /(2000 \mathrm{~km})$ has been chosen for the imposed sea-level gradient. Larger values will of course produce circulations with proportionately larger amplitudes.

Before concluding this section it should be noted that in the present formulation the effect of baroclinicity can be incorporated in an ad hoc fashion: Baroclinic effects over the slope will tend to reduce the friction parameter there. But a reduction in $r_{2}$ is equivalent to an increase in $s_{2}$ in $\epsilon_{2}=r /\left(f s_{2} L\right)$. Hence one can gain some insight into one possible baroclinic effect by reducing $\epsilon_{2}$. 

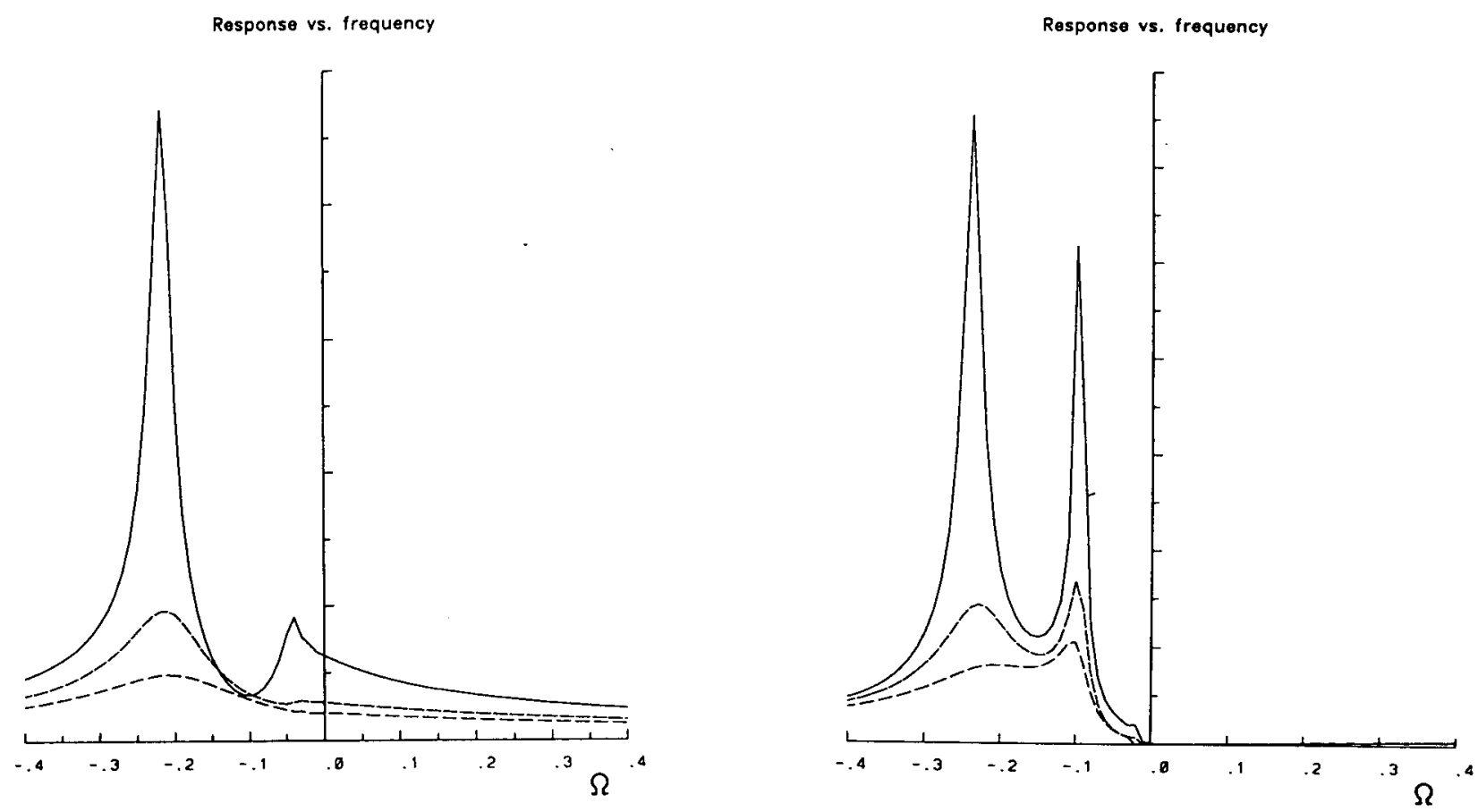

FIG. 11. In both graphs the response is plotted as a function of forcing frequency from $\Omega=-0.4$ up to $\Omega=+0.4$. Here the response is in fact the amplitude of the surface displacement at a mid-shelf location. The plot on the left shows the response to wind forcing while that on the right is for forcing by an APG. In both graphs the three curves correspond to different values of the linear friction parameter: $r=1.0 \times 10^{-4} \mathrm{~m} \mathrm{~s}^{-1}$ (solid), $r=5.0 \times 10^{-4} \mathrm{~m} \mathrm{~s}^{-1}$ (broken) and $r=10.0 \times 10^{-4} \mathrm{~m} \mathrm{~s}^{-1}$ (dashed).

\section{Free waves and their role in the forced response}

\section{a. Modal frequency}

Two types of modes need to be considered:

Type I which satisfy $\zeta_{x}\left(\delta_{2}\right)=0$ (cases 1 and 3 ), Type II which has $\zeta\left(\delta_{2}\right)=0$ (case 2 ).

Multiplying (3.3) by $\eta^{*}$, the complex conjugate of $\eta$, and then integrating over the margin leads to

$$
=\frac{\int_{0}^{\delta_{2}}\left|\eta_{n}\right|^{2} d X+i \epsilon_{1} \int_{0}^{\delta_{1}}\left|\eta_{n}^{\prime}\right|^{2} d X+i \epsilon_{2} \int_{\delta_{1}}^{\delta_{2}}\left|\eta_{n}^{\prime}\right|^{2} d X}{\int_{0}^{\delta_{2}} X\left|\eta_{n}^{\prime}\right|^{2} d X},
$$

where $\Omega_{n}$ is the nondimensional frequency of the $n$th mode (of either type) with corresponding cross-shelf structure $\eta_{n}=\eta_{n}(X)$. The unidirectional propagation property and the fact that only decaying modes are possible follows from the conditions that $\operatorname{Re}\left\{\Omega_{n}\right\}<0$ and $\operatorname{Im}\left\{\Omega_{n}\right\}<0$.

Setting $b_{1}=b_{4}=0$ in the matrix equation (3.15) provides the homogeneous boundary conditions satisfied by the free modes. For non-trivial solutions the determinant of the coefficient matrix in (3.15), ( $\Delta$ say) must vanish so that $\Delta_{1}=0$ (cases 1 and 3) and $\Delta_{2}=0$ (case 2). These two expressions determine the dependence of the modal frequencies upon the parameter $\epsilon$. The $\operatorname{Re}\{\Omega\}$ and $\operatorname{Im}\{\Omega\}$ are measures of the phase speed and the degree of damping, respectively. The complex roots of $\Delta_{1}$ and $\Delta_{2}$ have been calculated numerically and are presented in Figs. 12a,b, respectively. Most of the important features can be obtained analytically.

Since $\delta_{2} \int_{0}^{\delta_{2}}\left|\eta_{n}^{\prime}\right|^{2} d X$ provides an upper bound on the denominator in (4.1),

$$
-\frac{\int_{0}^{\delta_{2}}\left|\eta_{n}\right|^{2} d X}{\delta_{2} \int_{0}^{\delta_{2}}\left|\eta_{n}^{\prime}\right|^{2} d x} \text { and }-i \epsilon_{2} / \delta_{2}
$$

provide upper bounds on the real and imaginary parts of $\Omega_{n}$, respectively.

The functional $\int_{0}^{\delta_{2}}|\phi|^{2} d X / \int_{0}^{\delta_{2}} X /\left.\phi^{\prime}\right|^{2} d X$ is in fact maximized by the inviscid modal structures (Courant and Hilbert, 1953), in which case it equals $\left|\Omega_{n}(\epsilon=0)\right|$. Thus any modification in $\eta$ will reduce this ratio, and so the phase speeds of the frictional modes are all bounded above by the phase speed of their inviscid counterparts. This result remains true for all reasonable depth profiles, by a similar argument. Frictional values less than about $4.0 \times 10^{-4} \mathrm{~m} \mathrm{~s}^{-1}$ reduces the phase speeds of the first modes of both types by less than $5 \%$, 


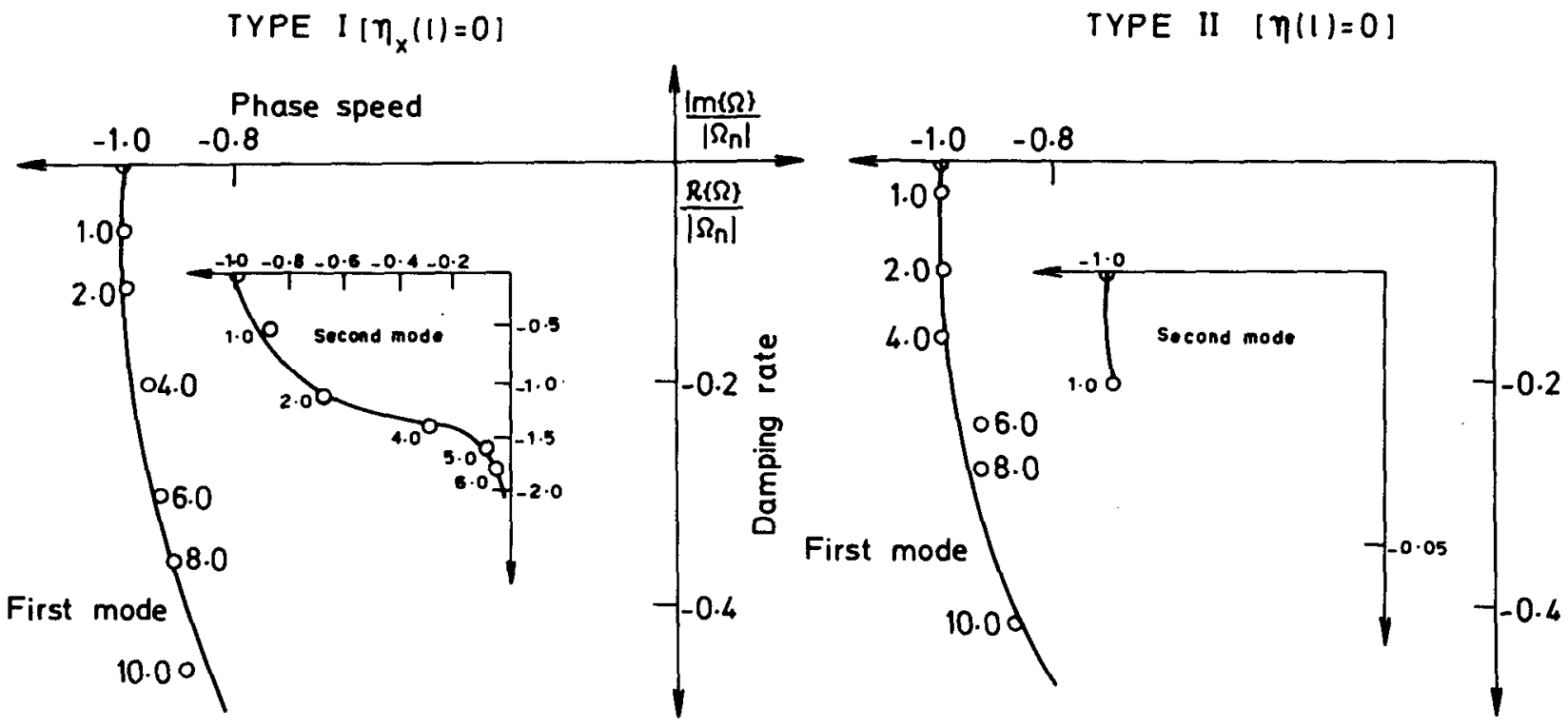

FIG. 12. Solutions of (a) $\Delta_{1}=0$ (Type I) and (b) $\Delta_{2}=0$ (Type II) which correspond to the first and second frictionally modified modes on a margin with $l_{2}=150 \mathrm{~km}, s_{1}=2.0 \times 10^{-3}$ and $s_{2}=76.0 \times 10^{-3}$ giving $h_{2}=4 \mathrm{~km}$. Here, $\Omega_{n}$ is the frequency of the $n$th inviscid mode. The data points represent modal frequencies at increasing values of $\epsilon$ multiplied by 1000 for convenience. $\operatorname{Re}\{\Omega\}$ and $\operatorname{Im}\{\Omega\}$ can be considered as the dimensionless phase speed and damping rate, respectively.

while the phase speed of the second mode (Type I) is reduced to only about $30 \%$ of its inviscid value.

Powers et al. plotted analogous graphs for free modes over depth profiles with constant slopes, but their primary interest was in the shelf circulation and so they did not exploit the fact that the inclined beach can also model a continental margin. For example, in their Fig. $10 r \approx 2 \epsilon$ if $s=4 \mathrm{~km} / 65 \mathrm{~km}, k=2 \pi / 2000 \mathrm{~km}$ ) and $f=10^{-4} \mathrm{~s}^{-1}$. Hence their simpler model predicts that the phase speed of the first mode will be virtually unaffected for $r \leqslant 5.0 \times 10^{-4} \mathrm{~m} \mathrm{~s}^{-1}$ ) while the second mode will have a phase speed which is only one half that of its inviscid value (if $r=5.0 \times 10^{-4} \mathrm{~m} \mathrm{~s}^{-1}$ ) for the shelf they considered, i.e., one which is $65 \mathrm{~km}$ wide. The numerical technique employed here failed to locate the frequency of the second, Type II mode when $r$ exceeded $2.0 \times 10^{-4} \mathrm{~m} \mathrm{~s}^{-1}$. However, the previous figure (Fig. 11) indicates that there is no reason to expect anything other than the same qualitative dependence of frequency upon friction as displayed by Type I modes.

\section{b. Modal structure}

Normalized modes are given by

$\hat{\eta}_{n}= \begin{cases}A_{n} I_{0}\left(\xi_{1 n}(X)\right)+B_{n} K_{0}\left(\xi_{1 n}(X)\right), & \text { shelf } \\ C_{n} I_{0}\left(\xi_{2 n}(X)\right)+K_{0}\left(\xi_{2 n}(X)\right), & \text { slope }\end{cases}$

where $C_{n}=-K / I$ and $K=-K_{1}\left(\xi_{n}\left(\delta_{2}\right)\right), I=I_{1}\left(\xi_{2 n}\left(\delta_{2}\right)\right)$ for Type I modes and $K=K_{0}\left(\xi_{2 n}\left(\delta_{2}\right)\right), I=I_{0}\left(\xi_{2 n}\left(\delta_{2}\right)\right)$ for Type II modes.
Continuity of pressure and the coastal boundary condition then gives

$$
\begin{aligned}
& A_{n}=\frac{I K_{020}-I_{020} K}{I_{011} K_{110}+I_{110} K_{011}} \frac{K_{110}}{I} \\
& B_{n}=\frac{I_{110}}{K_{110}} A_{n},
\end{aligned}
$$

respectively.

The modal structures have been found not to vary significantly over realistic ranges of the frictional parameter $r$. Type I modes 1 and 2 (Fig. 13a and b, respectively) and Type II modes 1 and 2 (Fig. 14a and $\mathrm{b}$, respectively) are presented. In each case $s_{1}=2.0$ $\times 10^{-3}, s_{2}=76.0 \times 10^{-3}, l_{1}=100 \mathrm{~km}, l_{2}=150 \mathrm{~km}$. A comparison between these figures and the forced results described in the previous section illustrates the dominance of these modes when $\Omega<0$. For example, Type I mode 1 dominates the forced response in Fig. 6 when $l_{2}=200 \mathrm{~km}$, Type II, mode 2 dominates the forced response in Fig. 10 on the narrow margin while mode 3 dominates the response when $l_{2}=150 \mathrm{~km}$. Note that the slight mismatch in $\zeta$ and $|\hat{\mathbf{U}}|$ at the shelfbreak in Figs. 13a and $14 \mathrm{~b}$ is due to errors in the numerically determined zeros of the determinants described in section $4 \mathrm{a}$ and plotted in Fig. 12. This mismatch occurs at the shelf break rather than at the coast or the edge of the margin because of the order in which the constants $A_{n}, B_{n}$ and $C_{n}$ were evaluated. We determined $C_{n}$ first and then $B_{n} / A_{n}$ so that the boundary conditions are satisfied exactly even if the numerically determined frequency is inaccurate. 

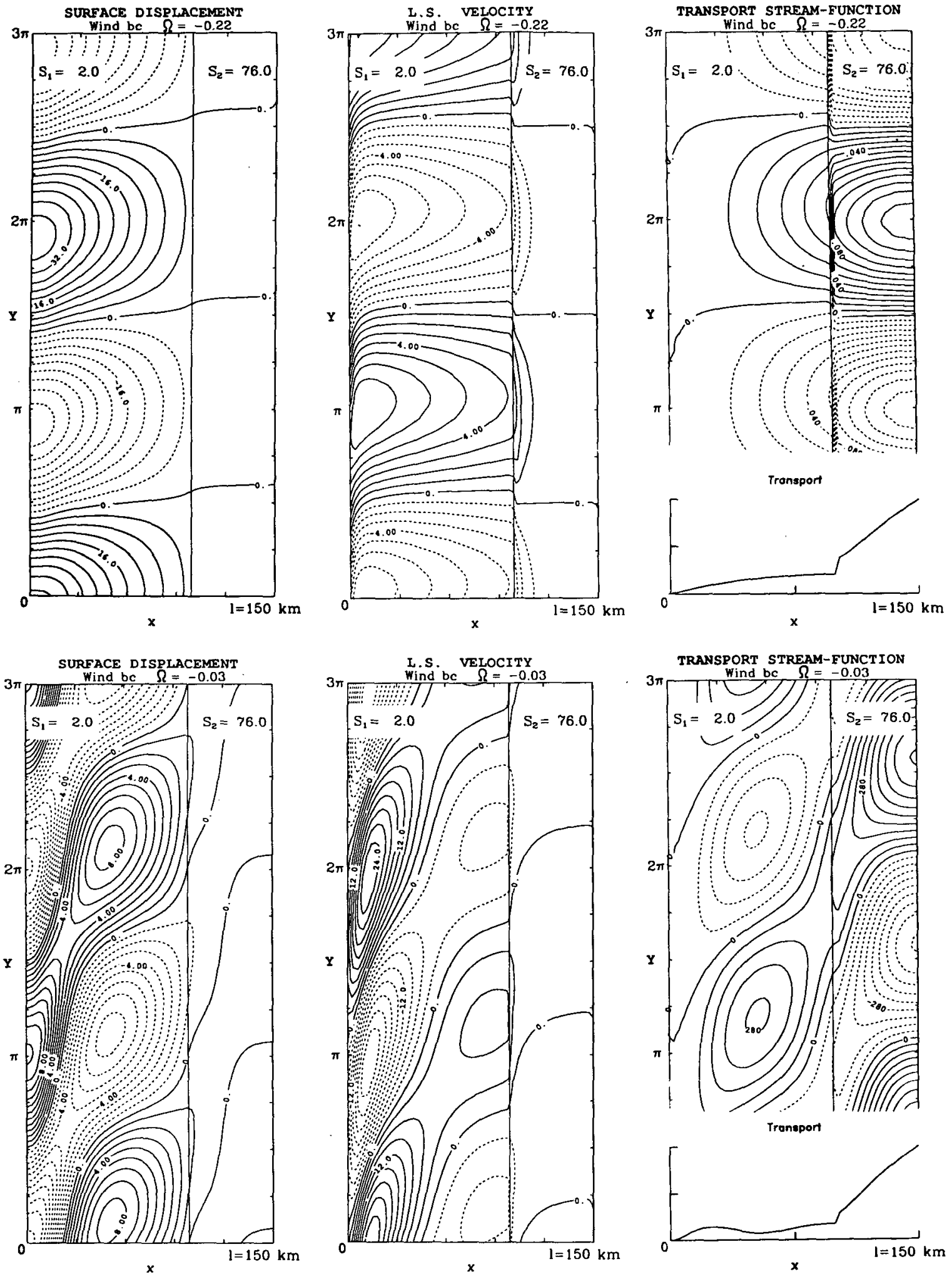

Fig. 13. Structure of the Type I modes with contours of surface displacement on the left, longshore velocity in the middle and transport on the right. Plots for both the (a) first and (b) second modes are presented for $l_{2}=150 \mathrm{~km}, r=1.0 \times 10^{-4} \mathrm{~m} \mathrm{~s}^{-1}, s_{1}$ $=2.0 \times 10^{-3}$ and $s_{2}=76.0 \times 10^{-3}$. The graph set in the contours of the transport streamfunction shows the magnitude of the transport across the margin. 

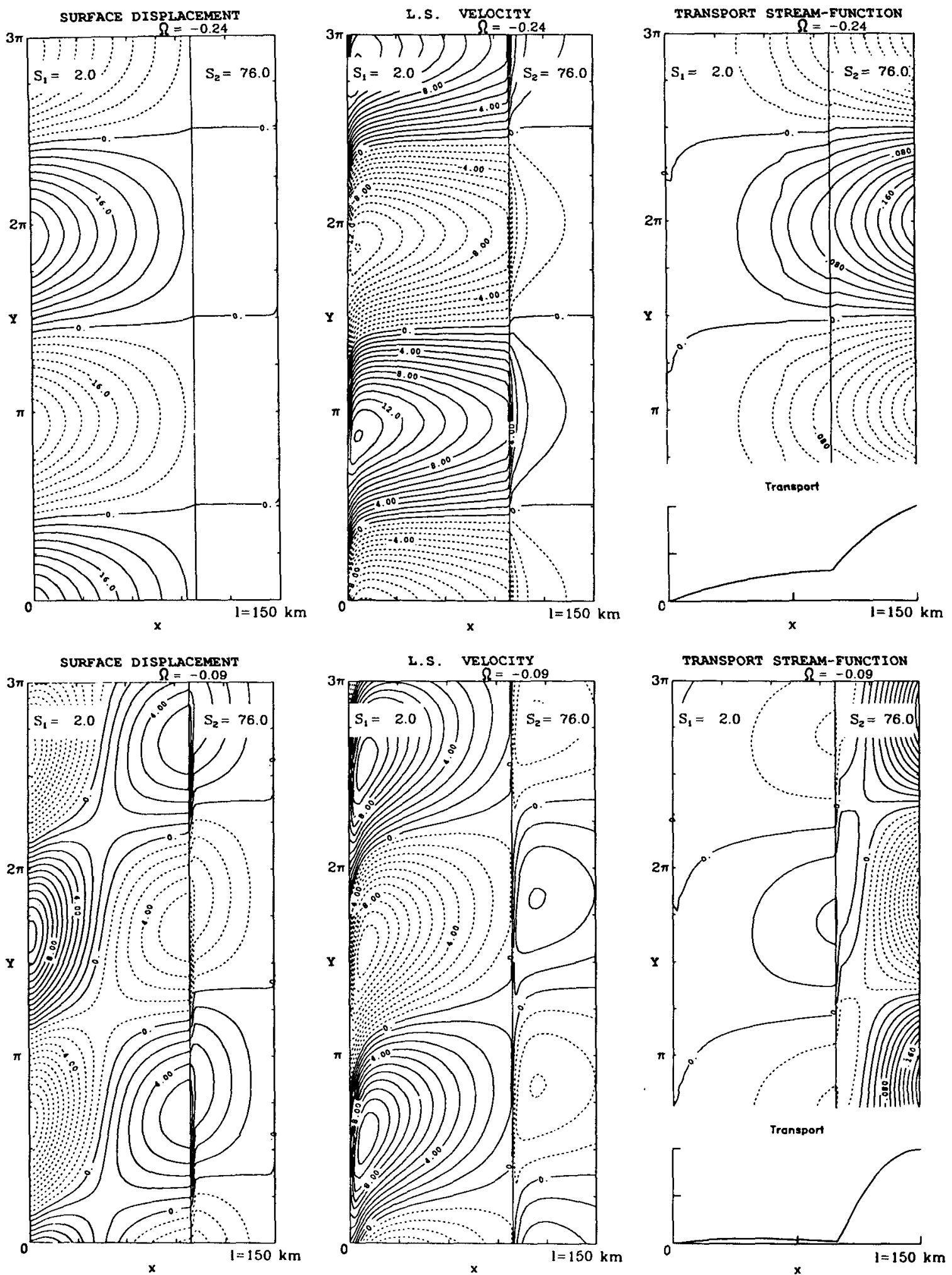

FIG. 14. Structure of Type II (a) mode 1 and (b) mode 2 for the same parameter values as those in Fig. 13. Again, the inset shows the transport across the margin. 


\section{Discussion}

A simple, barotropic model for the circulation over a bilinear continental margin (the shelf and slope considered as a whole) has been developed for forcing which varies sinusoidally in time and space alongshore. Three major alongshore forcing mechanisms have been considered: wind-stress, oceanic pressure gradients and oceanic currents. Mathematically, the model leads to a boundary value problem whose solution is straightforward. The governing equation is the same in all three cases, the general solution consisting of complex modified Bessel functions multipled by constants with values determined by the type of forcing applied. Two types of free modes can be supported: the first with $\zeta_{x}$ $=0$, the second with $\zeta=0$ at the boundary between the continental margin and the deep ocean. For a margin with a shelf $100 \mathrm{~km}$ wide, a slope of $50 \mathrm{~km}$ wide, $s_{1}=2.0 \times 10^{-3}$ and $s_{2}=7.6 \times 10^{-2}$ giving an ocean depth of approximately $4 \mathrm{~km}$, the first modes of both types were found to be only slightly altered by friction except near the coast. Their phase speeds are little changed (at least $95 \%$ of their inviscid values) even at the relatively large frictional value of $r=5.0 \times 10^{-4}$ $\mathrm{ms}^{-1}$. The second mode (Type II) on the same margin, however, had its phase speed substantially reduced from its inviscid value by the same frictional value.

We now consider the forced responses and the role played by these modes in them. The arrested topographic wave solution (Csanady 1978) provides a good approximation to the wind-forced solution when the dimensionless frequency, $\Omega=\omega / f \geqslant 0$ (which corresponds to the forcing function either at rest or moving in the opposite direction to that in which free modes propagate) except that no significant longshore velocities occur on a slope which has a gradient $s_{2} \gg s_{1}$, the gradient of the shelf. When $\Omega<0$, however, resonances occur which the steady model cannot account for. In the resonant response corresponding to the first mode (Type I), maximum surface displacement, $\zeta$, occurs at the coast, with a nodal line over the midshelf (if $s_{1}$ $\left.\times s_{2}\right)$ or at the shelf break $\left(s_{1} \ll s_{2}\right)$. If $s_{1} \approx s_{2}$, $\zeta$ then recovers to a secondary maximum at the boundary between the continental margin and the deep ocean. If $s_{1} \ll s_{2}$, the shelf width provides the trapping width for the depth-averaged, longshore velocity $v$, beyond which $v \approx 0$. There is substantial shear on the coastal side of the shelf break. On wider margins resonances corresponding to the second mode occur at the winddriven band. The surface displacement, $\zeta$, is then a maximum away from the coast with $\zeta \approx 0$ along the shelf break. Significant longshore velocities are then trapped on the inner shelf. The structure of the transport streamlines, $\hat{\mathbf{U}}$, remain remarkably similar at all frequencies and on margins with widths ranging from below $100 \mathrm{~km}$ up to $200 \mathrm{~km}\left(s_{1}=2.0 \times 10^{-3}, s_{2}=6.0\right.$ $\times 10^{-2}$ ). Transports are typically greatest over the shelf except when the response is dominated by the first mode.
Attention is now given to the oceanic alongshore pressure gradient forced solutions. When $\Omega \geqslant 0$, the steady model having $\Omega=0$ (Middleton 1987) provides a good approximation for the parameter values considered here to the time-dependent results with the pressure and transport diminishing across the margin from maximum values at the deep-ocean boundary. Significant depth-averaged longshore velocities are found on the shelf with significant shear on the coastal side of the shelf break when $s_{1} \ll s_{2}$. When $\Omega<0$, however, resonances corresponding to the second and third modes can occur if $-0.05<\Omega<0$ for the margins considered. In the case of a mode 2 resonance $\zeta$ has a maximum at the coast while maximum $v$ occur nearshire if $s_{1} \approx s_{2}$ or at the shelf break if $s_{1} \ll s_{2}$. Maximum transports no longer occur at the edge of the margin. On wider margins at the same frequency, mode 3 resonances occur which have maximum $\zeta$ on the shelf near the shelf break with secondary maxima at the coast. Here again transports diminish from their maximum values at the ocean boundary but remain significant much closer to shore. The longshore velocity has a maximum on the slope near the shelf break, diminishes to zero at the shelf break and then recovers to a secondary maximum over the shelf. The forced response to an oceanic current is simply related to the solution driven by an alongshore pressure gradient: their surface displacements are proportional to within a known function of the dimensionless parameters $\Omega$ and $\delta_{2}$ (the margin width).

For all types of forcing, increased bottom friction reduces the response at resonance and broadens the range of frequencies over which the response is "nearresonant". The slowing of the free modes by bottom friction is clearly evident in the forced responses as a shifting, or detuning, of the resonant peaks to lower frequencies.

Acknowledgments. This work was supported by ARC grant A4883/574 and an Australian Postgraduate Research Award. Two anonymous reviewers provided helpful comments.

\section{REFERENCES}

Abramowitz, M., and I. A. Stegun, 1965: Handbook of Mathematical Functions. 1046 pp., Dover.

Aikman, F. III, H. W. Ou and R. W. Houghton, 1987: Current variability across the New England continental shelf break and slope. Contin. Shelf Res., 8, 625-651.

Birchfield, G. E., and A. T. Lunde, 1978: A time-dependent model of a coastal boundary layer, with friction. J. Geophys. Res., 83(C12), 6155-6162.

Brink, K. H., and J. S. Allen, 1978: On the effect of bottom friction on barotropic motion over the continental shelf. J. Phys. Oceanogr., 8, 919-922 (correction, J. Phys. Oceanogr., 13; 149150).

Buchwald, V. T., and J. K. Adams, 1968: The propagation of continental shelf waves. Proc. Roy. Soc., London, A305, 235-250.

Chapman, D. C., and K. H. Brink, 1987: Shelf and slope circulation induced by fluctuating offshore forcing. J. Geophys. Res., 92(C11), 11 741-11759. 
Courant, R., and D. Hilbert, 1953: Methods of Mathematical Physics, Vol. 1, $5.61 \mathrm{pp}$. Interscience.

Csanady, G. T., 1978: The arrested topographic wave. J. Phys. Oceanogr., 8, 47-62.

$\longrightarrow$ J. H. Churchill and B. Butman, 1988: Near-bottom currents over the continental slope in the Mid-Atlantic Bight. Contin. Shelf Res., in press.

Denbo, D. W., and J. S. Allen, 1983: Mean flow generation on a continental margin by periodic wind forcing. J. Phys. Oceanogr., $13,78-92$.

Freeland, H. J., F. M. Boland, J. A. Church, A. J. Clarke, A. M. G. Forbes, A. Huyer, R. L. Smith, R. O. R. Y. Thompson and N. J. White, 1986: The Australian Coastal Experiment: A search for coastal-trapped waves. J. Phys. Oceanogr., 16, 1230-1249.

Gill, A. E., and E. H. Schumann, 1974: The generation of long shelf waves by the wind. J. Phys. Oceanogr., 4, 83-90.

Joyce, T. M., 1984: Velocity and hydrographic structure of a Gulf Stream warm-core ring. J. Phys. Oceanogr., 14, 936-947.

Louis, J. P., and P. C. Smith, 1981: The development of the barotropic radiation field of an eddy over a slope. J. Phys. Oceanogr., 12, 56-73.

_ B. D. Petrie and P. C. Smith, 1982: Observations of topographic
Rossby waves on the continental margin off Nova Scotia. $J$. Phys. Oceanogr., 12, 47-55.

Maeland, E., 1983: On the response of a wind-driven current over a continental shelf. J. Geophys. Res., 88(C7), 4534-4538.

Middleton, J. H., 1987: Steady coastal circulation due to alongshore pressure gradients. J. Phys. Oceanogr., 17, 604-612.

Mysak, L. A., 1967: On the theory of continental shelf waves. $J$. Mar. Res., 25, 205-227.

Power, S. B., J. H. Middleton and R. H. J. Grimshaw, 1989: Frictionally modified continental shelf waves and the subintertial response to wind and deep ocean forcing. $J$. Phys. Oceanogr., 19, 1486-1506.

Robinson, A. R., 1964: Continental shelf waves and the response of the sea surface to weather systems. J. Geophys. Res., 69, 367368.

Romea, R. D., and J. S. Allen, 1982: On forced coastal trapped waves at low latitudes in a stratified ocean. J. Mar. Res., 40, 369-401.

Thompson, K. R., 1987: Time-dependent shelf circulation and the arrested topographic wave. J. Phys. Oceanogr., (submitted).

Weaver, A. J., and J. H. Middleton, 1989: On the dynamics of the Leeuwin Current. J. Phys. Oceanogr., 19, 626-648. 